\title{
Exploring Pupils' Mathematics Reading Performance Under Online Reading Environment
}

\author{
Yuan-Horng Lin*, Yi-An Chen \\ Department of Mathematics Education, National Taichung University of Education, Taichung City, Taiwan
}

Email address:

lyh@mail.ntcu.edu.tw (Yuan-Horng Lin), a0935632009@gmail.com (Yi-An Chen)

${ }^{*}$ Corresponding author

To cite this article:

Yuan-Horng Lin, Yi-An Chen. Exploring Pupils' Mathematics Reading Performance Under Online Reading Environment. Psychology and Behavioral Sciences. Vol. 5, No. 5, 2016, pp. 117-123. doi: 10.11648/j.pbs.20160505.11

Received: June 30, 2016; Accepted: August 26, 2016; Published: August 28, 2016

\begin{abstract}
The purpose of this research aims to investigate the performance of mathematics reading for pupils. Mathematics reading is nowadays an important issue which is the conjunction of mathematics proficiency and reading comprehension. Besides, online reading becomes widespread owing to the development of internet technology. Development of mathematics reading articles in the online system to detect the performance of pupils should be a prospective research. However, little is known about the performance of mathematics reading and its effects under online reading environment. In this study, there are two articles of mathematics reading established in the online environment. Contents of mathematics reading are related to factor and multiple contexts. The participants include 117 fifth grades in Taiwan. Theoretical frame is based on theory of subject reading components proposed by M. C. McKenna and R. D. Robinson (2002). These components are general reading comprehension, prior knowledge of mathematics and mathematics-specific literacy skills. According to the data analysis, pupils perform the best on general reading comprehension. In addition, they perform the worst on mathematics-specific literacy skills. The results coincide with the findings of related literature. However, there is no difference on these three components between genders. Results of this study could furnish the theory and practice of online mathematics reading. Finally, based on the findings, some suggestions and recommendations for future research and practical instruction of mathematics reading are discussed.
\end{abstract}

Keywords: Factor and Multiple, Mathematics Reading, Online Reading, Reading Comprehension

\section{Introduction}

Mathematics and reading play an important role in students' learning. Mathematical logic and reasoning thinking are essential parts of reading and verb comprehension. Reading itself is a complex information processing. Readers attempt to construct a meaning representation that addresses the goal. Reading comprehension is also the fundamental process for mathematical problem solving $[1,21]$. Many studies highlight the importance of the need for the understanding and awareness of math vocabulary in order to achieve problem solving. Some kinds of survey aim to find out what difficulties students were having and carry out some methods to improve students' ability to solve problems. They conclude the comprehension of reading mathematics vocabulary should be an influential factor.
M. L. Barton and C. Heidema claim why reading in mathematics is important. They indicate the fact that a mathematics text demands readers to use additional, content-specific reading skills. It is [3].

Students must be able to read not only from left to right, as they do in other subject areas, but also from right to left (consider an integer number line), from top to bottom or vice versa (with tables), and even diagonally (with some graphs) [3].

Mathematics has been considered the fundamental literacy and tool to understand other content knowledge such as nature science and engineering. Nowadays, mathematical literacy is associated with reading. Reading and mathematics always consolidate to formulate the mathematical literacy. As M. Siegel and J. M. Fonzi indicated, reading to learn mathematics in classroom involves helping students better comprehend the language, syntax and logic of math content as well as learning to read a wide range of real life texts 
involving mathematics [4]. They proposed inquiry-based instruction to help students learn to think mathematically as well as value both the aesthetics and the applicability of mathematics. Categories of reading practices in an inquiry-oriented mathematics classroom include five categories. These five categories are reading to make public, reading to comprehend, reading to get an example, reading to generate something new and reading to remember [4]. Reading to make public suggests that meaning demonstrate one's thinking. Reading to comprehend is to make sense of text and extract specific information. Reading to get an example means how to do something the text does and how to show an example of something. Reading to generate something new is to push something further and create alternate ideas. Reading to remember is to value the thinking and copy from the meaning. In according to this point, mathematics reading not only emphasizes comprehension of word problems in the math textbook, bust also highlights the reading for popularization of mathematics article. Therefore, mathematics learning and reading activity should be integrated so as to enhance students' literacy [5]. M. C. McKenna and R. D. Robinson conceived the cognitive components of content literacy in the reading activity included three components [6]. As shown in Figure 1, these three components are prior knowledge of content, general literacy skills and content-specific literacy skills. Components of mathematics reading can be established by analogy with the viewpoints in Figure 1.

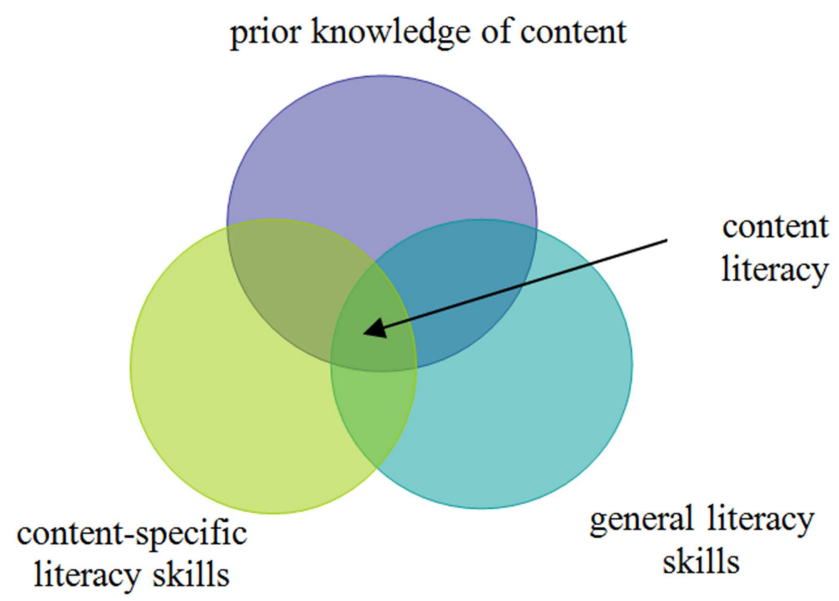

Figure 1. Cognitive components of content literacy (McKenna \& Robinson, 2002, p. 7).

The Internet has been considered the useful technology for literacy and learning in the 21 st century. It is an efficient system in the history of civilization for people to read and communicate effectively. The new literacy of online reading comprehension is recognized as the core curriculum and assessment of the Common Core State Standards for the English language arts in the United States [7]. Reading comprehension is one aspect of literacy where change and information occur. Online reading comprehension is not isomorphic with off line reading comprehension. Additional practices, skills, and strategies for online reading appear to be necessary [8]. However, research concerning online mathematics reading is little known and it should be a prospective issue worthy of investigating.

Concept and application of multiple and factor are an important topic and mathematics curriculum in elementary schools. It is concluded that usage of multiplicative structure in reasoning process needs to deal flexibly with multiples and factors through the application of meaningful processes. As A. Brown, K. Thomas and G. Tolias stated [9],

A major goal of experiences of this type would be not only to teach students procedures (actions) needed for dealing with numbers in prime-factored form, but to get students to reflect on these actions sufficiently and in productive enough ways that they are able to move beyond successful actions to processes and objects. (p. 78)

Meanings of multiple and factor always happen in daily life. However, concepts of multiple and factor are quite abstract. Although students know their mathematical concepts, they always encounter difficulty about using these concepts while solving word problems. Further, problem solving and application related to concepts of lowest common multiple (LCM) and greatest common factor (GCM) are one of elementary mathematics topics that students have difficulties. Multiplicative structure is an important process that students should know about multiple and factor [9]. In order to improve students' multiple and factor concepts, technology learning and visual learning are considered to be an effective way $[11,12]$. Since concepts and applications of multiple and factor lie in daily life, it is prospective to enhance understanding of multiple and factor by the activity of mathematics reading.

\section{Literature Review}

\subsection{Mathematics Learning and Reading}

Learning mathematics is to deal with concepts as ideas or abstractions which learners must bring together to solve mathematical problems to understand the real world. In this process of learning mathematics, learners think in terms of symbolic representation and abstract conceptualization. Systematical plan and concrete reality always include mathematical modeling. Finally, solutions of problems are applied and explained in real situation mathematics.

Reading is one of the prerequisite abilities for learning mathematics. Reading in mathematics needs to realize the images, notions and connotations. Word problems and articles are popular reading materials for in mathematics reading activities [13]. Students need to construct meaning for vocabulary terms and connect to prior mathematics knowledge as well as to new mathematics concepts. Besides, mathematics reading is often considered an effective way to improve numeracy and mathematical literacy. T. Shanahan and C. Shanahan argued that disciplinary literacy is an advanced literacy instruction embedded within content-area classes. They proposed reading comprehension strategies might best fit particular in disciplinary reading tasks. Basic 
literacy includes decoding and knowledge of high-fluency words which are entailed in all reading task. Intermediate literacy includes generic comprehension strategies and common word meaning. Discipline literacy is specialized skills to subject matter, such as math. The literacy is constructed in a progressive model of pyramid. The literacy progress model is as the Figure 2 [15],

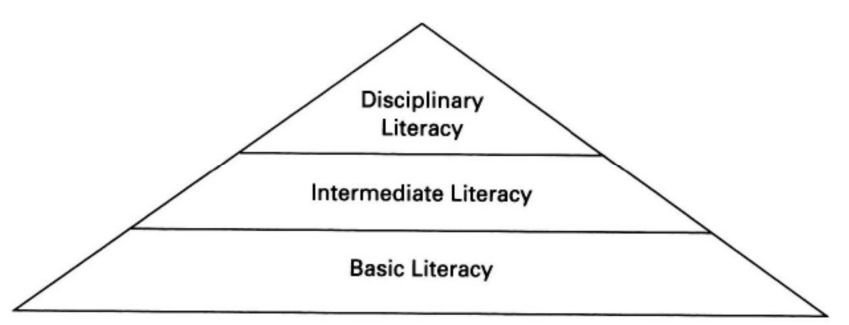

Figure 2. The increasing model of literacy progress (Shanahan \& Shanahan, 2008, p.40).

Reading comprehension is the foundation of literacy and it overlaps with mathematical comprehension. When students are involved in mathematics reading activity, mathematical representations and semantic structures are in turn be expressed linguistically. Linguistic descriptions in quantitative or mathematical terms are influential factor for reading comprehension. Students often attempt to get gist while reading mathematics texts or articles. This kind of reading requires a precision of meaning and each mathematics vocabulary word must be understood specifically [2].

A reading protocol is a set of strategies that a reader must adopt in order to benefit completely from reading the text. Mathematics has it own reading protocol and therefore students must learn to read mathematics. As to mathematics article, the beauty itself is in the elegant efficient way to concisely describe precise ideas of great complexity. Mathematical ideas are well defined and precise descriptions are always in a very short space.

Mathematics reading can bring positive effects for mathematics learning. The benefits of mathematics reading go beyond simply learning mathematics. Students read to learn mathematics and explain their mathematical ideas in prose. Mathematics reading in classroom encompasses explaining mathematics, communicating mathematics and other deeper learning mathematics.

\subsection{Concepts of Factors and Multiples in Mathematics}

Number concept is the basis of mathematics learning. Natural number is the rudimentary knowledge to students. In elementary school mathematics, factor and multiple are defined coordinately. Given the two positive integer $a$ and $b$, $a$ is called the factor of $b$ if $b$ is divided by a without remainder. In other words, $b$ is the multiple of $a$. Based on the point, concepts and skills of integer numbers, multiplication and division are the pre-requisite of factor and multiple [10].

Some literatures find that students have misconceptions and difficulties when learning multiple and factor. Realistic mathematic instruction should be the core of multiple and factor concepts. Designed situational problems can support students' ability to understand LCM (least common multiple) concept and to generate students' learning trajectory in learning of LCM. Learning stages vary from understanding concept of factor, multiple and strategies adoption could improve students' ability forming situational problems to formal representation [16].

C. Hsieh and S. Lin employed the Excel function to design dynamic visual activities for students to learn factors and multiples word problems. Experiments showed that elementary schools students had greater progress in understanding core concepts when they used multiple-linked representations activities. Students can solve the problems successfully and they also mastered the relations in various external representations while understanding word problem transformation becomes an internal representation [11]. $\mathrm{H}$. Çamli and J. Bintaş investigated the effects of computer aided instruction on students' performance in solving problems related to multiples and factors with multiplicative structures. The experimental instruction design showed that the use of computer support in teaching and learning lowest common multiple and greatest common factor problems and multiplicative structures in mathematics lesson may increase students academic success [17].

\subsection{Online Reading and Empirical Studies}

Modern information and communication technologies (ICT) has widely influenced our learning [22]. Hence, we human need new literacy for learning and life. The Internet and online information are new technologies which challenge students' abilities to comprehend informational text. As The RAND Reading Study Group (RRSG, 2002) reported [19],

Electronic texts that incorporate hyperlinks and hypermedia... require skills and abilities beyond those required for the comprehension of conventional, linear print (p. 14).

Reading on the Internet is one kind of online reading which reading process differs from traditional reading. Recent researches suggest that the skills and strategies required to comprehend printed text are intertwined with another complex skills and strategies to achieve successful reading comprehension on the Internet $[18,20]$.

Reading and mathematics now become important literacy for citizens of all nations. Dynamic computer-based learning environment which addresses the connections between linguistic and conceptual meaning can help students explore connections between representations and analogous representations of the problem immediately. The online mathematics reading process can help students understand word problems and hence succeed in problem solving [14]. Since reading on the Internet is a essential ability for students. It is prospective to investigate the performance of students' mathematics reading on the Internet. 


\section{Research Design}

\subsection{Components and Content of Mathematics Reading}

In accordance with literatures of mathematics reading and the cognitive components of content literacy provided by $\mathrm{M}$. C. McKenna and R. D. Robinson [6], this study proposed three cognitive components of mathematics reading. It is shown as Figure 3.

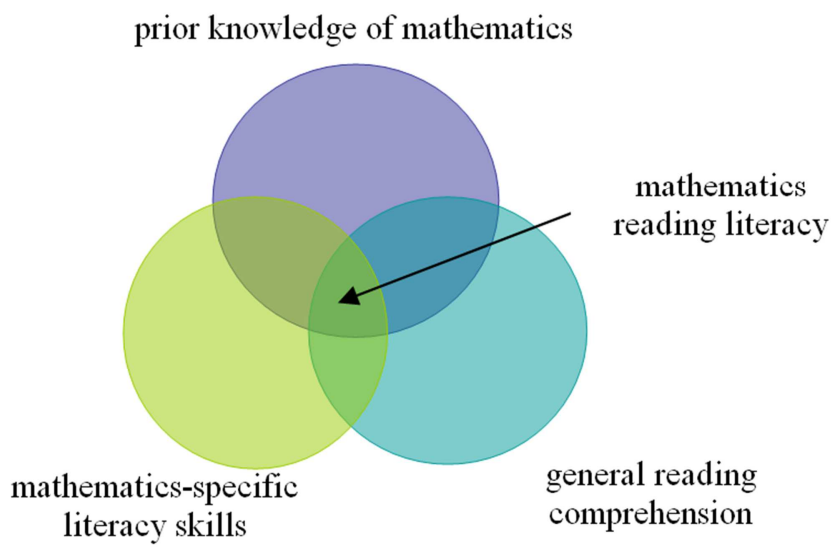

Figure 3. Cognitive components of mathematics reading literacy.

The study designs two mathematics reading articles. Content of these two articles is related to issue of multiples and factors. Descriptions and textures are life mathematics and close to students' experiences. As to each article, the main text is a story telling of mathematics reading which is 200-300 words long (Chinese character). Each mathematics reading assessment follows one mathematics reading article and these two mathematics reading assessments are denoted as I and II.

As shown in Figure 3, the mathematics reading assessment consists of three cognitive components of mathematics reading, which are general reading comprehension, prior knowledge of mathematics and mathematics-specific literacy skills. In this study, each mathematics reading assessment consists of 4 items respective to each cognitive component of mathematics reading. There are 8 items within each cognitive component of mathematics reading in total. Each item corresponds to one attribute which is belonged to certain cognitive component and examined by mathematics experts. Hence, the content validity of assessment is set up already.

\subsection{Subject and Online Reading Platform}

Firstly, 78 fifth graders in Taiwan participates the pilot study. Results of pilot study assessment show that difficulties (correct ratio) of all items vary from 0.34 to 0.92 . Discrimination index (Pearson correlation coefficient) shows all correlation coefficients are significantly positive correlation. Cronbach reliability of the assessments is .92 ., which means that the difficulty, discrimination and reliability of the assessment are acceptable.

Mathematics reading articles are written in Chinese character. Subject of this study is 117 fifth graders in Taiwan. The researchers establish the platform and build the mathematics reading articles and assessments in the platform. Students login and enter the platform to do the online reading and after finishing one article reading, they must take its assessmen. While taking assessments, students can also go back to read and check the article. The reading behavior and activity is almost like the paper form reading. The total time of reading and assessment activities is within 40 minutes. All the response data is stored in back end of the platform and the researchers could access the response database. The main screen of mathematics reading and the screen of reading and assessment are shown as Figure 4 and Figure 5.

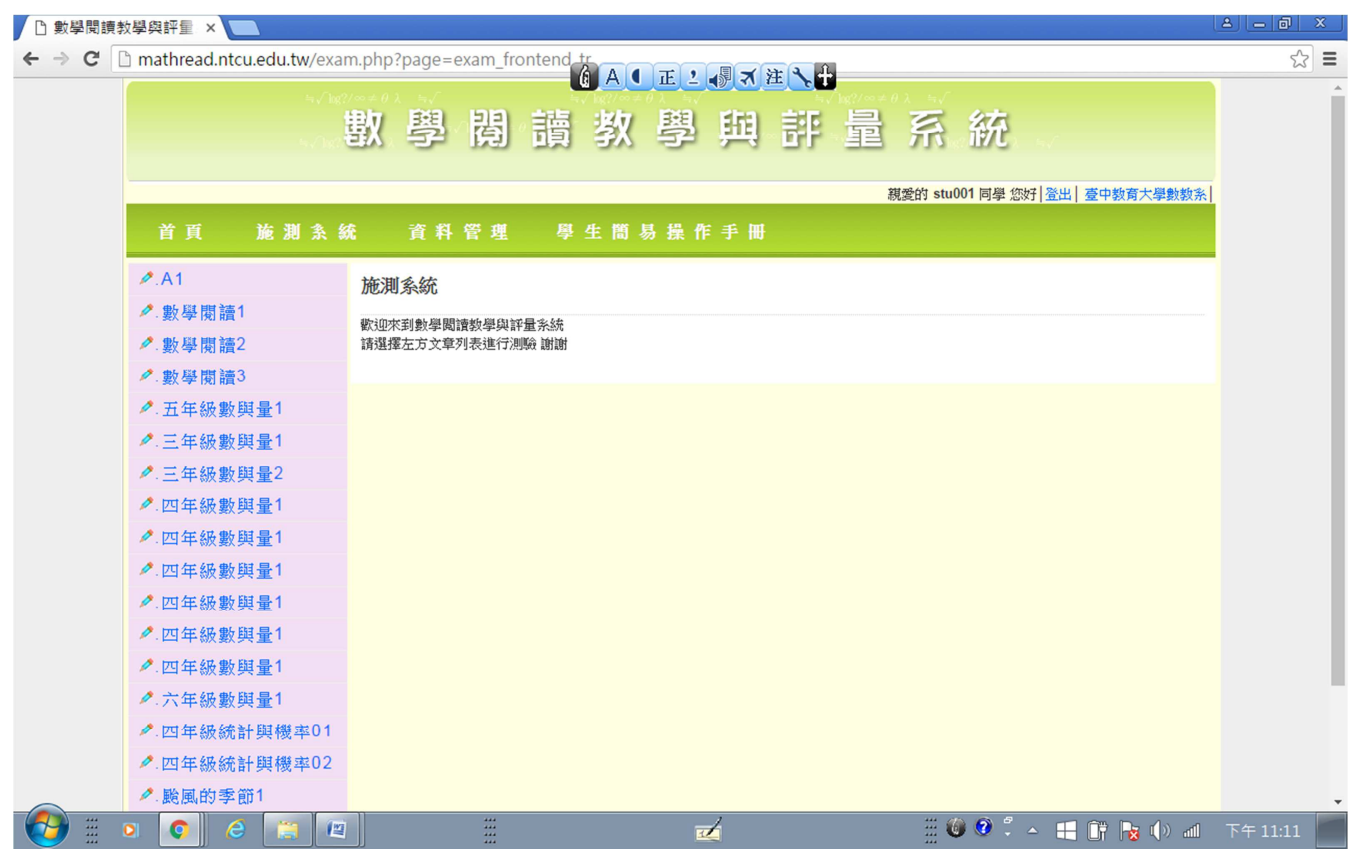

Figure 4. The main screen of mathematics reading platform (Chinese character). 


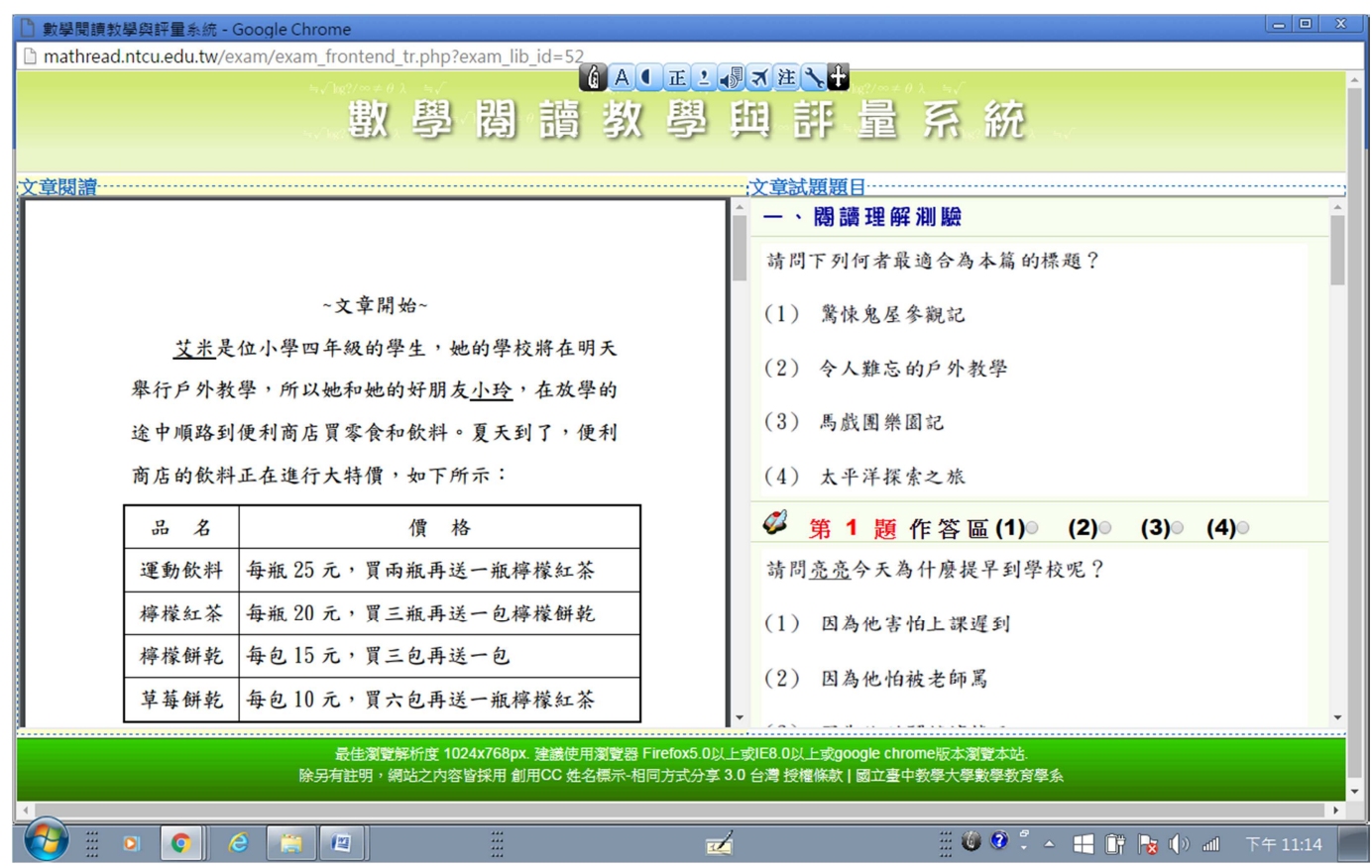

Figure 5. The screen of reading and assessment platform (Chinese character).

\section{Results and Discussions}

\subsection{Statistics Description of Mathematics Reading Performance}

There are two mathematics reading articles in this study. Statistics descriptions and mean comparisons as to mathematics reading performance of students are shown in Table 1. In terms of mathematics reading assessment, full of score respective to each cognitive component within one assessment is 4 . It reveals that students have the highest mean score on general reading comprehension and have the lowest mean score on mathematics-specific literacy skills.

Table 2 is the statistics test on mean comparisons among cognitive components. These two mathematics reading assessments indicate there exist significantly difference among cognitive components.

Table 1. Mean and standard deviation of cognitive components.

\begin{tabular}{lll}
\hline \multirow{2}{*}{ Cognitive components } & \multicolumn{2}{l}{$\begin{array}{l}\text { Mathematics reading assessment } \\
\text { (mean and SD) }\end{array}$} \\
\cline { 2 - 3 } & I & II \\
\hline general reading comprehension & $3.47(0.73)$ & $3.79(0.48)$ \\
prior knowledge of mathematics & $2.63(1.10)$ & $3.05(0.89)$ \\
mathematics-specific literacy skills. & $2.21(1.08)$ & $2.16(1.11)$ \\
\hline
\end{tabular}

Table 2. Mean comparisons among cognitive components.

\begin{tabular}{lll}
\hline \multirow{2}{*}{ Cognitive components } & \multicolumn{2}{l}{ t-test of mathematics reading assessment } \\
\cline { 2 - 3 } & I & II \\
\hline C1-C2 & $7.24^{* * *}$ & $7.83^{* * *}$ \\
C1-C3 & $11.42^{* * *}$ & $14.98^{* * *}$ \\
C2-C3 & $3.33^{* *}$ & $7.73^{* * *}$ \\
\hline
\end{tabular}

$* * \mathrm{p}<.01 * * * \mathrm{p}<.001$

$\mathrm{C} 1$ : general reading comprehension

$\mathrm{C} 2$ : prior knowledge of mathematics

C3: mathematics-specific literacy skills
It requires to further investigation into the relationship among cognitive components. Table 3 and Table 4 depict that there is only positive correlation between prior knowledge of mathematics and mathematics-specific literacy skills. The result implies that general reading comprehension is a unique dimension concerning mathematics reading. Prior knowledge of mathematics and mathematics-specific literacy skills may positively influence and twist with each other when students are reading online mathematics articles.

Table 3. Correlation coefficient matrix for cognitive components of mathematics reading assessment $I$.

\begin{tabular}{llll}
\hline Cognitive components & C1 & C2 & C3 \\
\hline C1 & & & \\
C2 & 0.10 & & \\
C3 & 0.18 & $0.22 *$ & \\
\hline
\end{tabular}

$* \mathrm{p}<.05$

$\mathrm{C} 1$ : general reading comprehension

$\mathrm{C} 2$ : prior knowledge of mathematics

C3: mathematics-specific literacy skills

Table 4. Correlation coefficient matrix for cognitive components of mathematics reading assessment II.

\begin{tabular}{llll}
\hline Cognitive components & C1 & C2 & C3 \\
\hline C1 & & & \\
C2 & 0.04 & & \\
C3 & 0.06 & $0.24^{*}$ & \\
\hline
\end{tabular}

${ }^{*} \mathrm{p}<.05$

$\mathrm{C} 1$ : general reading comprehension

$\mathrm{C} 2$ : prior knowledge of mathematics

C3: mathematics-specific literacy skills 


\subsection{Comparisons on Mathematics Reading Performance Between Genders}

Some literatures indicate that gender differs in reading comprehension. However, other literatures don't come to the same. Therefore, it is prospective to compare mean on mathematics reading performance as to gender. As shown in Table 5 and Table 6, they reveal that there is no difference regarding all cognitive components of mathematics reading between male and female. This new finding is similar to some literatures with regard to reading comprehension.

Table 5. Mean comparisons on mathematics reading performance assessment I between genders.

\begin{tabular}{lllll}
\hline \multicolumn{2}{l}{ Cognitive component description } & & & \multirow{2}{*}{ t-test } \\
\cline { 1 - 4 } Cognitive components & Gender & Mean & SD & \\
\cline { 1 - 2 } general reading & male & 3.4667 & .70028 & \multirow{2}{*}{0.02} \\
comprehension & female & 3.4643 & .76192 & \\
prior knowledge of & male & 2.5333 & 1.15666 & \multirow{2}{*}{1.06} \\
mathematics & female & 2.7500 & 1.03133 & \\
mathematics-specific literacy & male & 2.1333 & 1.06511 & \multirow{2}{*}{0.67} \\
skills & female & 2.2679 & 1.08697 & \\
\hline
\end{tabular}

Table 6. Mean comparisons on mathematics reading performance assessment II between genders.

\begin{tabular}{llllll}
\hline \multicolumn{2}{l}{ Cognitive component description } & & & \multirow{2}{*}{ t-test } \\
\cline { 1 - 4 } Cognitive components & Gender & Mean & SD & \\
\cline { 1 - 2 } general reading & male & 3.7667 & .49972 & \multirow{2}{*}{-0.61} \\
comprehension & female & 3.8214 & .47125 & \\
prior knowledge of & male & 2.9833 & .92958 & \multirow{2}{*}{-0.85} \\
mathematics & female & 3.1250 & .85413 & \\
mathematics-specific & male & 2.1167 & 1.19450 & \multirow{2}{*}{-0.39} \\
literacy skills & female & 2.1964 & 1.01658 & \\
\hline
\end{tabular}

\section{Conclusions}

Mathematics reading is one of important mathematics learning activities and is also considered the manifest outcome of mathematical literacy. However, little is known about the performance of cognitive components as to pupils' online mathematics reading. This study develops mathematics reading articles and platform. Results show the hierarchies among of cognitive components. This study also reveals only positive correlation between prior knowledge of mathematics and mathematics-specific literacy skills. In addition, there is no difference between mathematics reading performance and gender. Future studies can focus on the psychological mechanism of mathematics reading. All these findings in this study could provide teachers and students with suggestions and references for learning and instruction activities regarding mathematics reading.

\section{Acknowledgements}

This research was supported by Ministry of Science and Technology of Taiwan, R. O. C. under grant MOST 104-2511-S-142-003-MY3.

\section{References}

[1] Vilenius-Tuohimaa, P. M., Aunola, K., \& Nurmi, J. E. (2008). The association between mathematical word problems and reading comprehension. Educational Psychology, 28 (4), 409-426.

[2] Huntsinger, C. S., Jose, P. E., Larson, S. L., Balsink Krieg, D., \& Shaligram, C. (2000). Mathematics, vocabulary, and reading development in Chinese American and European American children over the primary school years. Journal of Educational Psychology, 92 (4), 745.

[3] Barton, M. L. \& Heidema, C. (2002). Teaching reading in mathematics (2nd ed.). Aurora, Colorado: Mid-continent Research for Education and Learning.

[4] Siegel, M., \& Fonzi, J. M. (1995). The practice of reading in an inquiry-oriented mathematics class. Reading Research Quarterly, 632-673.

[5] Draper, R. J. (2002). School mathematics reform, constructivism, and literacy: A case for literacy instruction in the reform-oriented math classroom. Journal of Adolescent \& Adult Literacy, 45 (6), 520-529.

[6] McKenna, M. C., \& Robinson, R. D. (2002). Teaching through text: A content literacy approach to content area reading. Boston, MA: Allyn \& Bacon.

[7] Leu, D. J., Gregory McVerry, J., Ian O'Byrne, W., Kiili, C., Zawilinski, L., Everett-Cacopardo, H., Kennedy, C. \& Forzani, E. (2011). The new literacies of online reading comprehension: Expanding the literacy and learning curriculum. Journal of Adolescent \& Adult Literacy, 55 (1), 5-14.

[8] Coiro, J., \& Dobler, E. (2007). Exploring the online reading comprehension strategies used by sixth-grade skilled readers to search for and locate information on the Internet. Reading Research Quarterly, 42 (2), 214-257.

[9] Brown, A., Thomas, K., \& Tolias, G. (2002). Conceptions of divisibility: Success and understanding. In Stephen Campbell and Rina Zazkis (Eds), Learning and teaching number theory: Research in cognition and instruction (pp. 41-82). Westport: Ablex publishing.

[10] Dias, A. (2005). Using lattice models to determine Greatest Common Factor and Least Common Multiple. International Journal for Mathematics Teaching and Learning. 730-738.

[11] Hsieh, C., \& Lin, S. (2008). Dynamic visual computer design for factors and multiples word problem learning. International Journal of Mathematical Education in Science and Technology, 39 (2), 215-232.

[12] Çaml1, H., \& Bintaş, J. (2009). Mathematical problem solving and computers: Investigation of the effect of computer aided instruction in solving lowest common multiple and greatest common factor problems. Journal of Human Sciences, 6 (2), 348-356.

[13] Vilenius-Tuohimaa, P. M., Aunola, K., \& Nurmi, J. E. (2008). The association between mathematical word problems and reading comprehension. Educational Psychology, 28 (4), 409-426.

[14] Leblanc, M. D. (1991). From natural language to mathematical representations: A model of mathematical reading. Digital Creativity, 2 (3-4), 149-158. 
[15] Shanahan, T., \& Shanahan, C. (2008). Teaching disciplinary literacy to adolescents: Rethinking content-area literacy. Harvard Educational Review, 78 (1), 40-59.

[16] Triyani, S., Ilma, R., \& Darmawijoyo, D. (2014). Supporting Student's Ability in Understanding Least Common Multiple (LCM) Concept Using Storytelling. Journal on Mathematics Education, 3 (2), 151-164.

[17] Çamli, H., \& Bintaş, J. (2009). Mathematical problem solving and computers: Investigation of the effect of computer aided instruction in solving lowest common multiple and greatest common factor problems. Journal of Human Sciences, 6 (2), 348-356.

[18] Coiro, J. (2011). Predicting reading comprehension on the internet contributions of offline reading skills, online reading skills, and prior knowledge. Journal of Literacy Research, 43 (4), 352-392.
[19] RAND Reading Study Group. (2002). Reading for understanding: Toward an R\&D program in reading comprehension. Santa Monica, CA: RAND.

[20] Coiro, J., \& Dobler, E. (2007). Exploring the comprehension strategies used by sixth-grade skilled readers as they search for and locate information on the Internet. Reading Research Quarterly, 42, 214-257.

[21] Österholm, M. (2006). Characterizing reading comprehension of mathematical texts. Educational Studies in Mathematics, 63 (3), 325-346.

[22] Drijvers, P. (2015). Digital technology in mathematics education: why it works (or doesn't). In Selected Regular Lectures from the 12th International Congress on Mathematical Education (pp. 135-151). Springer International Publishing. 